\title{
The relation between performance and oral health in male athletes
}

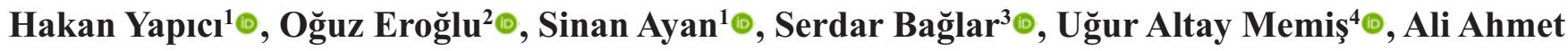 \\ Doğan'®
}

${ }^{1}$ Kırıkkale University, School of Physical Education and Sports, Kırıkkale, Turkey

${ }^{2}$ Department of Emergency Medicine, Kırlkkale University School of Medicine, Kirlkkale, Turkey

${ }^{3}$ Department of Operative Dentistry, Kirlkkale University, Faculty of Dentistry, Kirlkkale, Turkey

${ }^{4}$ Bülent Ecevit University, School of Physical Education and Sports, Zonguldak, Turkey

DOI: $10.18621 /$ eurj.432272

\begin{abstract}
Objectives: .Oral health is as important to an athlete's sporting successas regular exercise and adequate nutrition. The aim of this study was to investigate the relation between oral health and sporting performance. Methods: This prospective study was carried out with male athletes. Athletes' demographic characteristics, dental care habits, number of decayed, missing or filled teeth, and sporting performance data were recorded. The Decayed Missing Filled Teeth (DMFT) index, Significant Caries index (SCI) and Plaque index (PI) were used to assess oral health. The T-Drill, Zig-Zag, Lateral Change of Direction (LCD) and 505 tests to assess agility, and 10-, 20- and 30-m short sprint tests were used to assess speed. The results were analyzed on SPSS software, and $p$ values $<0.05$ were regarded as significant.

Results: Ninety-six athletes were included in the study. Active caries was determined in $70.8 \%$. The mean DMFT index value was $3.9 \pm 3.7$, mean SCI 10.2, and mean PI $0.9 \pm 0.4$. DMFT was $\geq 4$ in $45.8 \%$ of athletes and $<4$ in $57.2 \%$. No difference was determined between subjects with DMFT $<4$ and DMFT $\geq 4$ in terms of age, height, body weight, or years engaged in sports. Agility and speed tests results were superior in subjects with DMFT $<4$ than in those with DMFT $\geq 4$, and times to completion of performance tests were shorter $(p<$ 0.05). Pearson correlation analysis revealed that DMFT was positively correlated with agility tests [T-Drill test $(\mathrm{r}=0.428)$, Zig-Zag test $(\mathrm{r}=0.428)$, LCD test $(\mathrm{r}=0.286)$ and 505 test $(\mathrm{r}=0.529)$ ], and speed tests [short sprint, 10-m $(\mathrm{r}=0.309), 20-\mathrm{m}(\mathrm{r}=0.336), 30-\mathrm{m}(\mathrm{r}=0.449)](p<0.05)$.

Conclusion: Impairment of oral health has an adverse effect on sporting performance, and this can lead to poorer results in performance tests such as agility and speed.
\end{abstract}

Keywords: Athletes, athletic performance, oral health, tooth

Received: June 8, 2018; Accepted: October 13, 2018; Published Online: October 15, 2018

A n athlete's success is closely associated with physical and mental health [1]. Oral and dental health is one of the principal indicators of quality of life and general physical health, not only in athletes but in the general population [2]. In addition to gingi- val bleeding, dental caries, and tooth loss, poor oral health can also lead to several systemic diseases [3, 4]. Studies have shown that poor oral health is associated with weight loss, growth delay, coronary artery disease, constipation, and immune system weakness

Address for correspondence: Oğuz Eroğlu, MD., Assistant Professor, Kurlkkale University School of Medicine, Department of Emergency Medicine, 71850 Kirlkkale, Turkey

E-mail: oguzerogluacil@gmail.com,Tel: +90 3183330000 (5192),Fax: +90 3182240786 
[5-8]. Oral health evaluation is based on various parameters, including numbers of decayed, missing or filled teeth, dental erosion, plaque levels, and gingival bleeding. Frequently employed tools include Decayed Missed Filled Teeth (DMFT) index, the Significant Caries index (SCI) and Green and Vermillion's Plaque index (PI) [9-12].

Studies have reported poor oral and dental health in both professional and amateur athletes [13-15]. While this is linked to dental decay occurring in association with frequent consumption of carbohydrates, a good energy source, or energy drinks containing high acid and carbohydrate levels, particularly during exercise, it is also related to individual factors such as nutrition or tooth brushing habits [16, 17]. Compromise of oral health in athletes can affect performance in terms of speed, strength, power, flexibility, and agility, and these changes in performance can be shown by means of tests, both in the field and in the laboratory [18-20].

The aim of this study was to investigate the relation between oral health and athletic performance.

\section{METHODS}

\section{Study Design}

Approval for the study was granted by the local ethics committee (No. 2012/12-02). This prospective study of male athletes was performed by the Kirikkale University Department of Physical Education and Sports, Department of Oral Health and Dentistry, and Department of Emergency Medicine in November 2013. Information about the study aim was given to all athletes participating, and all provided informed consent. The study was performed in accordance with the Declaration of Helsinki and the Good Clinical Practice Directive.

Demographic data (age, height, body weight, sports age, heart rate, and fat measurements), oral health, numbers of decayed, missed and filled teeth, teeth brushing behaviors, and speed and agility test results were recorded for all subjects.

\section{Assessment of Oral Health and Dental Care}

Oral health and dental care examinations were conducted separately for all subjects. All oral and dental health examinations were carried out at the
Kurıkkale University Faculty of Dentistry and by the same experienced dentist. The Green and Vermillion PI was used to evaluate oral hygiene, while assessment of decayed, missed or filled teeth was based on the DMFT index. The SCI indexwas used to evaluate the prevalence of caries in groups of individuals. Care was taken during oral health examinations to adhere to World Health Organization oral health and dental care rules[10, 11, 21-23].

\section{Assessment of Speed and Agility}

Athletes' performance tests were conducted at the Kirıkkale University Faculty of Physical Education and Sports gymnasium. Calibration and linearity settings of the instruments used in the measurements were completed before the performance tests. Height, weight and body composition measurements were performed using a Tanita body composition analyzer (Tanita Body Composition Analyzer BC 418 professional model, USA). All athletes were familiarized with the performance test procedures through practice in the gymnasium before the final tests. In order to prevent fatigue, athletes were instructed to avoid intense exercise for the 24 -h period before the testing session. We used 10-, 20-, and 30$\mathrm{m}$ short sprint tests to assess speed, and the T-Drill test, Zig-Zag test, 505 test, and Lateral Change of Direction (LCD) test to evaluate agility [24]. All tests were performed three times, and the best results were recorded.

\section{Statistical Analysis}

All data were analyzed on SPSS 18.0 (Statistical Package for the Social Sciences Inc., Chicago, IL, USA) software. Data obtained from the performance tests exhibited normal distribution and are expressed as mean \pm standard deviation (SD). The independent samples t-test was used to compare the test results between the DMTF $<4$ and DMTF $\geq 4$ groups. We also determined relations between DMTF and different performance tests using Pearson correlations (r) and determination $\left(\mathrm{r}^{2}\right)$ coefficients. The $p$ values $<$ 0.05 were regarded as statistically significant.

\section{RESULTS}

Ninety-six male athletes were included in the 
Table 1. Relations between athletes' demographic data and the DMFT index

\begin{tabular}{lcccc}
\hline & DMFT & n & mean \pm SD & p value \\
\hline Age (years) & $\geq 4$ & 41 & $20.29 \pm 1.15$ & 0.308 \\
Height (cm) & $<4$ & 55 & $20.58 \pm 1.51$ & \\
& $\geq 4$ & 41 & $1.77 \pm 0.76$ & 0.698 \\
Weight (kg) & $<4$ & 55 & $1.78 \pm 0.61$ & \\
& $\geq 4$ & 41 & $72.48 \pm 14.04$ & 0.344 \\
Years in sport & $<4$ & 55 & $70.30 \pm 8.29$ & \\
& $\geq 4$ & 41 & $7.1 \pm 2.5$ & 0.76 \\
\hline
\end{tabular}

DMFT $=$ Decayed missing filled teeth, $\mathrm{SD}=$ standard deviation

study. The mean age of the athletes was $20.4 \pm 1.3$ years, mean body mass index (BMI) was $22.01 \pm 2.3$ $\mathrm{kg} / \mathrm{m}^{2}$, mean body weight was $71.2 \pm 11.0 \mathrm{~kg}$, mean height was $178.4 \pm 0.7 \mathrm{~cm}$, mean body fat was $12.6 \pm$ $2.5 \%$, and mean heart rate was $68.2 \pm 5.2$ beats $/ \mathrm{min}$ (resting state). The participants had been actively engaged in sports for a mean $6.6 \pm 2.6$ years and trained 3-4 times a week (for a total of 6-8 hours a week). Twenty-five (26.1\%) attended regular dental check-ups. Twenty-eight (29.2\%) brushed their teeth twice or more a day. However, only thirty-eight $(39.6 \%)$ used dental floss or mouth rinses. The most frequently reported symptom was gingival bleeding (66.8\%).

The mean DMFT index value was $3.9 \pm 3.7$ based on the following component measures: mean number of teeth with active caries $2.7 \pm 2.9$, missing teeth 0.6 \pm 1.1 , and filled teeth $0.5 \pm 1.4$. Forty-one athletes (42.7\%) had DMFT $\geq 4$ and 55 (57.3\%) had DMFT $<$ 4. The mean SCI value was 10.2, and the prevalence of caries was $66 \%$. The mean PI score was $0.9 \pm 0.4$. Twenty-eight (\%29.2) athletes had non-carious teeth and $70.8 \%$ carious teeth.

There was no significant difference between the DMFT $\geq 4$ and DMFT $<4$ groups in terms of age, height, weight or years engaged in sport $(p>0.05)$ (Table 1).

A difference was determined between the DMFT $\geq 4$ and DMFT $<4$ groups in terms of decayed, missing, and filled teeth $(p<0.01, p<0.01$, and $p<0.05$, respectively). The most important factor affecting DMFT values was the number of decayed teeth (Table 2).

The DMFT $<4$ group was more successful than the DMFT $\geq 4$ group in the agility tests (T-drill, ZigZag, LCD, and 505) and speed tests (10-, 20-, and 30 -m short sprint) $(p<0.05)$. Success rates decreased as DMFT values increased. Increased DMFT values were associated with prolonged times to completion of agility and speed tests. Analysis of t values in the agility tests revealed that the most significant difference was in the Zig-Zag tests, while the greatest difference in the speed test was observed in the $20-\mathrm{m}$ sprint test (Table 3).

Table 2. Comparison of athletes with DMFT $<4$ and with DMFT $\geq 4$ in terms of numbers of decayed, missing and filled teeth

\begin{tabular}{lcccc}
\hline $\mathbf{n = 9 6}$ & DMFT & min-max & mean \pm SD & p value \\
\hline \multirow{2}{*}{ Decayed } & $\geq 4$ & $0-11$ & $4.97 \pm 3.12$ & $<\mathbf{0 . 0 1}$ \\
& $<4$ & $0-3$ & $1.04 \pm 1.02$ & \\
Filled & $\geq 4$ & $0-7$ & $1.24 \pm 1.93$ & $<\mathbf{0 . 0 1}$ \\
\multirow{2}{*}{ Missing } & $<4$ & $0-1$ & $0.09 \pm 0.29$ & \\
& $\geq 4$ & $0-4$ & $1.20 \pm 1.29$ & $<\mathbf{0 . 0 5}$ \\
Total & $<4$ & $0-3$ & $0.18 \pm 0.51$ & \\
& $\geq 4$ & $4-15$ & $7.39 \pm 3.00$ & $<\mathbf{0 . 0 1}$ \\
\hline
\end{tabular}

$\mathrm{DMFT}=$ Decayed missing filled teeth, $\mathrm{SD}=$ standard deviation, $\min =$ minimum, $\max =$ maximum 
Table 3. Analysis of performance test results by DMFT index scores

\begin{tabular}{|c|c|c|c|c|c|}
\hline$n=96$ & & DMFT & $\min -\max$ & mean $\pm \mathrm{SD}$ & $p^{*}$ value \\
\hline \multirow{6}{*}{ Agility } & \multirow{2}{*}{ T-Drill test (sec) } & $\geq 4$ & $9.14-13.78$ & $11.33 \pm 1.06$ & \multirow{2}{*}{$<0.05$} \\
\hline & & $<4$ & $9.06-13.50$ & $10.64 \pm 0.91$ & \\
\hline & \multirow{2}{*}{ Zig-Zag test (sec) } & $\geq 4$ & $5.64-7.34$ & $6.47 \pm 0.40$ & \multirow{2}{*}{$<0.05$} \\
\hline & & $<4$ & $5.08-6.86$ & $6.03 \pm 0.39$ & \\
\hline & \multirow{2}{*}{505 test $(\mathrm{sec})$} & $\geq 4$ & $2.27-4.44$ & $3.02 \pm 0.47$ & \multirow[b]{2}{*}{$<0.05$} \\
\hline & & $<4$ & $2.31-3.53$ & $2.77 \pm 0.36$ & \\
\hline & \multirow{2}{*}{ LCD test(sec) } & $\geq 4$ & $4.70-7.44$ & $6.12 \pm 0.61$ & \multirow{2}{*}{$<0.05$} \\
\hline & & $<4$ & $4.22-7.12$ & $5.64 \pm 0.73$ & \\
\hline \multirow{6}{*}{ Speed } & \multirow{2}{*}{10 m sprint best (sec) } & $\geq 4$ & $1.59-2.75$ & $1.99 \pm 0.29$ & \multirow{2}{*}{$<0.05$} \\
\hline & & $<4$ & $1.56-2.38$ & $1.85 \pm 0.18$ & \\
\hline & \multirow{2}{*}{20 m sprint best (sec) } & $\geq 4$ & $2.34-3.10$ & $2.63 \pm 0.21$ & \multirow{2}{*}{$<0.05$} \\
\hline & & $<4$ & $1.75-2.81$ & $2.47 \pm 0.21$ & \\
\hline & \multirow[b]{2}{*}{30 m sprint best (sec) } & $\geq 4$ & $3.24-5.56$ & $4.25 \pm 0.60$ & \multirow{2}{*}{$<\mathbf{0 . 0 5}$} \\
\hline & & $<4$ & $3.16-4.78$ & 3.890 .50 & \\
\hline
\end{tabular}

DMFT $=$ Decayed missing filled teeth, $\mathrm{SD}=$ standard deviation, $\min =$ minimum, $\max =$ maximum, ${ }^{*}$ The independent samples t-test

The results showed that the correlation coefficient values of the agility and speed tests were all significant $(p<0.01)$. Positive correlations were observed between the DMFT index and performance tests. This correlation was especially significant in the Zig-Zag test (among the agility tests) and in the $30-\mathrm{m}$ sprint test (among the speed tests) (Table 4).

\section{DISCUSSION}

A successful athlete must always take regular exercise andreceive balanced nutrition, and must always keep his body healthy and prepared. As also reported in previous studies, considering the link between oral and dental health, general health, and adequate nutrition, these play a significant role in athletic performance, and impairment of oral health has a negative effect on sporting performance $[2,3$, $25,26]$. The findings from our study show that an increasing number of decayed, missing and filled teeth has an adverse impact on performance, and prolongs the completion of both agility and speed tests.

Studies of professional and non-professional athletes in various different spheres have evaluated athletes in terms of oral health, nutritional habits, and saliva profiles [13-15, 27, 28]. Ashley et al. [25] reported poor oral health in professional athletes, with a dental caries rate of $15-75 \%$, and a dental erosion rate of 36-85\%, while Gay-Escoda et al. [14] reported a gingival bleeding rate of $60 \%$. Using a similar method to that in our study, Forrest [29] evaluated numbers of decayed, missing, and filled teeth in Olympic and non-Olympic athletes and reported DMFT indices of 2.8 to 16.8. In two different studies of footballers, de Sant'Anna et al. [15] reported

Table 4. Correlation between performance tests and the DMFT index

\begin{tabular}{llccc}
\hline Relation to DMFT & & $\mathbf{r}$ & $\mathbf{r}^{\mathbf{2}}$ & $\boldsymbol{p}^{*}$ value \\
\hline \multirow{2}{*}{ Agility } & T- Drill test & 0.428 & 0.18 & $<\mathbf{0 . 0 1}$ \\
& Zig-Zag test & 0.529 & 0.28 & $<\mathbf{0 . 0 1}$ \\
& 505 test & 0.286 & 0.08 & $<\mathbf{0 . 0 1}$ \\
LCD test & 0.398 & 0.15 & $<\mathbf{0 . 0 1}$ \\
Speed & 10-m sprint best & 0.281 & 0.08 & $<\mathbf{0 . 0 1}$ \\
& 20-m sprint best & 0.309 & 0.09 & $<\mathbf{0 . 0 1}$ \\
\hline
\end{tabular}

DMFT $=$ Decayed missing filled teeth, Pearson correlations $(\mathrm{r})$ and determination $\left(\mathrm{r}^{2}\right)$ coefficients.

*The independent samples t-test 
DMFT $=8$, and SCI $=12$, while another study reported findings of DMFT $=5.7 \pm 4.1$, and $\mathrm{SCI}=10$ in the Barcelona soccer team [14]. In our study, dental decay was determined in $70.8 \%$ of athletes and gingival bleeding in $66.8 \%$, whilethe mean DMFT score was $3.9 \pm 3.7$, mean $\mathrm{SCI}=10.2$, and mean $\mathrm{PI}=$ $0.9 \pm 0.4$. Our results are in agreement with those of previous studies, and suggest that Turkish athletes, like those in other parts of the world, do not attach sufficient importance to oral and dental health.

Several studies have investigated the effect of oral health on physical performance. However, these studies have reported general conclusions that poor oral health has an adverse impact on physical performance. Needleman et al. [30] reported that approximately half of footballers in the United Kingdom were troubled by poor oral health, and that some experienced decreased quality of life and physical performance due to poor oral health. In studies of Olympic athletes, most subjects have reported decreased performance due to poor oral health, while some have even reported being prevented from training due to problems deriving from oral and dental health impairment [2, 29, 31, 32]. This led the International Olympic Committee to take action, and obliged it to issue calls to all relevant countries concerning oral health protection [33]. One more specific investigation of oral health and performance examined the link between oral health and grip strength and showed that poor oral health had an adverse effect on grip strength [34]. Iwasaki et al. [35] considered the subject from a different perspective and showed that poor oral health also caused compromise of cognitive functions. Our study investigated the relation between male athletes' oral health and sporting performances using previously developed performance tests [24]. In one previous study, Reilly et al. reported a mean 30-m short sprint time of $4.46 \pm 0.21 \mathrm{sec}$, while in our study the relevant timings were $4.25 \pm 0.60 \mathrm{sec}$ in subjects with DMFT $\geq 4$ and $3.89 \pm 0.50 \mathrm{sec}$ in those with DMFT $<4$ [36]. In their study of 106 professional athletes, Little et al. reported a $10-\mathrm{m}$ short sprint time of $1.83 \mathrm{sec}$, a $20-\mathrm{m}$ sprint time of $2.40 \mathrm{sec}$ and a mean Zig-Zag agility test time of $5.34 \mathrm{sec}$, while in our study these values were similar to those of professional athletes only in the subjects with DMFT $<4$, but were longer in those with DMFT $\geq 4$ [37]. Similarly,in their study of agility in footballers, Hoffman et al reported a mean T-Drill test time of $9.36 \pm 0.44 \mathrm{sec}$, while in our study this time was only approached by athletes withDMFT $<4$ (Tdrill agility test results; DMFT $<4=10.64 \pm 0.91 \mathrm{sec}$; DMFT $\geq 4=11.33 \pm 1.06 \mathrm{sec}$ ) [38]. It would appear that an increased number of decayed, missing or filled teeth has an adverse impact on physical performance. This thesis is supported by all agility and speed test results being better in athletes with better oral health, with DMFT $<4$, than in those with DMFT $\geq 4$.

\section{Limitations}

There are a number of limitations to our study. First, although athletes were asked to rest in the period before the tests were to be performed, some may not have complied. This may have affected the results obtained in the performance tests. Second, since only male athletes were included in the study, the results obtained cannot be generalized to all athletes. Wideranging performance studies also including female athletes are therefore needed.

\section{CONCLUSION}

In conclusion, the data we obtained show that impairment of oral health in male athletes, in other words an increasing number of decayed, missing or filled teeth or gingival bleeding, has an adverse effect on physical performance and that this results in slower times in tests of physical performance, such as speed and agility, and to poorer outcomes.

\section{Conflict of interest}

The authors disclosed no conflict of interest during the preparation or publication of this manuscript.

\section{Financing}

The authors disclosed that they did not receive any grant during conduction or writing of this study.

\section{REFERENCES}

[1] Bryant S, McLaughlin K, Morgaine K, Drummond B. Elite athletes and oral health. Int J Sports Med 2011;32:720-4.

[2] Needleman I, Ashley P, Petrie A, Fortune F, Turner W, Jones $\mathrm{J}$, et al. Oral health and impact on performance of athletes 
participating in the London 2012 Olympic Games: a crosssectional study. Br J Sports Med 2013;47:1054-8.

[3] Locker D. Measuring oral health: a conceptual framework. Community Dent Health 1988;5:3-18.

[4] Cullinan MP, Seymour GJ. Periodontal disease and systemic illness: will the evidence ever be enough? Periodontol 2000 2013;62:271-86.

[5] Tenovuo J, Lehtonen OP, Aaltonen A. Caries development in children in relation to the presence of mutans streptococci in dental plaque and of serum antibodies against whole cells and protein antigen I/II of Streptococcus mutans. Caries Res 1990;24:59-64.

[6] Mattila K, Valtonen V, Nieminen M, Huttunen JK. Dental infection and the risk of new coronary events: prospective study of patients with documented coronary artery disease. Clin Infect Dis 1995;20:588-92.

[7] Cameron F, Weaver L, Wright C, Welbury R. Dietary and social characteristics of children with severe tooth decay. Scottish Med J 2006;51:26-9.

[8] Yoshihara A, Takano N, Hirotomi T, Ogawa H, Hanada N, Miyazaki H. Longitudinal relationship between root caries and serum albumin. J Dental Res 2007;86:1115-9.

[9] Antunes JLF, Narvai PC, Nugent ZJ. Measuring inequalities in the distribution of dental caries. Community Dent Oral Epidemiol 2004;32:41-8.

[10] World Health Organization: Significant Caries Index. http://www.whocollab.od.mah.se/sicdata.html. AoN, 2010.

[11] Prashanth S, Bhatnagar S, Das UM, Gopu H. Oral health knowledge, practice, oral hygiene status, and dental caries prevalence among visually impaired children in Bangalore. J Indian Soc Pedod Prev Dent 2011;29:102.

[12] Löe H. The gingival index, the plaque index and the retention index systems. J Periodontol 1967;38:610-6.

[13] Ljungberg G, Birkhed D. Dental caries in players belonging to a Swedish soccer team. Swedish Dent J 1990;14:261-6.

[14] Gay Escoda C, Pereira DMVD, Ardèvol J, Pruna R, Fernandez J, Valmaseda Castellón E. Study of the effect of oral health on physical condition of professional soccer players of the Football Club Barcelona. Med Oral Patol Oral Cir Bucal 2011;16:436-9.

[15] de Sant'Anna GR, Simianato MRL, Suzuki MES. Sports dentistry: buccal and salivary profile of a female soccer team. Quintessence Int 2004;35:649-52.

[16] Convertino VA, Armstrong LE, Coyle EF, Mack GW, Sawka MN, Senay JL, et al. American College of Sports Medicine position stand. Exercise and fluid replacement. Med Sci Sports Exerc 1996;28:1-7.

[17] Mobley CC. Nutrition and dental caries. Dent Clin North Am 2003;47:319-36.

[18] Sheppard JM, Young WB. Agility literature review: Classifications, training and testing. J Sports Sci 2006;24:91932.

[19] Tenenbaum G, Levy-Kolker N, Sade S, Liebermann DG, Lidor R. Anticipation and confidence of decisions related to skilled performance. Int J Sport Psychol 1996;27:293-307.

[20] Farrow D, Young W, Bruce L. The development of a test of reactive agility for netball: a new methodology. J Sci Med Sport
2005;8:52-60.

[21] Duričković M, Ivanović M. [The state of oral health in children at the age of 12 in Montenegro]. Vojnosanitetski Pregled 2011;68:550-5. [Article in Serbian]

[22] Oliveira LB, Zardetto CGDC, de Oliveira Rocha R, Rodrigues CRMD, Wanderley MT. Effectiveness of triple-headed toothbrushes and the influence of the person who performs the toothbrushing on biofilm removal. Oral Health Prev Dent 2011;9:137-41.

[23] Reddy ER, Rani ST, Manjula M, Kumar LV, Mohan TA, Radhika E. Assessment of caries status among schoolchildren according to decayed-missing-filled teeth/decayed-extract-filled teeth index, International Caries Detection and Assessment System, and Caries Assessment Spectrum and Treatment criteria. Indian J Dental Res 2017;28:487.

[24] Kutlu M, Yapici H, Yoncalik O, Celik S. Comparison of a new test for agility and skill in soccer with other agility tests. J Human Kinetics 2012;33:143-50.

[25] Ashley P, Di Iorio A, Cole E, Tanday A, Needleman I. Oral health of elite athletes and association with performance: a systematic review. Br J Sports Med 2015;49:14-9.

[26] Piccininni PM, Fasel R. Sports dentistry and the Olympic games. J Calif Dent Assoc 2005;33:471-83.

[27] Kerr L. Dental problems in athletes. Clin Sports Med 1983;2:115-22.

[28] Buyer DM. Are you drinking your teeth away? J Indiana Dent Assoc 2009;88:11-3.

[29] Forrest J. The dental condition of Olympic Games contestants: a pilot study, 1968. Dent Pract Dent Rec 1969;20:95101.

[30] Needleman I, Ashley P, Meehan L, Petrie A, Weiler R, McNally S, et al. Poor oral health including active caries in 187 UK professional male football players: clinical dental examination performed by dentists. Br J Sports Med 2016;50:414.

[31] Soler DB, Batchelor P, Sheiham A. The prevalence of oral health problems in participantsof the 1992 Olympic Games in Barcelona. Int Dent J 1994;44:44-8.

[32] Yang XJ, Schamach P, Dai JP, Zhen XZ, Yi B, Liu H, et al. Dental service in 2008 Summer Olympic Games. Br J Sports Med 2011;45:270-4.

[33] Ljungqvist A, Jenoure P, Engebretsen L, Alonso JM, Bahr $\mathrm{R}$, Clough A, et al. The International Olympic Committee (IOC) Consensus Statement on periodic health evaluation of elite athletes March 2009. Br J Sports Med 2009;43:631-43.

[34] Shiau YY, Wang JS, Carlsson GE. The effects of dental condition on hand strength and maximum bite force. Cranio 1993;11:48-54.

[35] Iwasaki M, Taylor GW, Manz MC, Yoshihara A, Sato M, Muramatsu K, et al. Oral health status: relationship to nutrient and food intake among 80-year-old Japanese adults. Community Dent Oral Epidemiol 2014;42:441-50.

[36] Reilly T, Atkinson G, Gregson W, Drust B, Forsyth J, Edwards B, et al. Some chronobiological considerations related to physical exercise. Clin Ter 2006;157:249-64.

[37] Little T, Williams AG. Effects of differential stretching protocols during warm-ups on high-speed motor capacities in 
professional soccer players. J Strength Cond Res 2006;20:2037.

[38] Hoffman JR, Cooper J, Wendell M, Kang J. Comparison of
Olympic vs. traditional power lifting training programs in football players. J Strength Cond Res 2004;18:129-35. 